\title{
Blunt trauma to the parotid gland
}

\author{
O D Smith^, D J McFerran, N Antoun
}

\begin{abstract}
Trauma involving the parotid gland is rare and is usually caused by penetrating injuries or fractures of the facial skeleton. A unique case is presented of rupture of the parotid gland after a minor external force in a 14 year old boy. The radiological findings are presented, which pointed to diffuse rupture of the gland parenchyma with an intact duct system. A conservative management policy using antibiotics and anticholinergics was effective, with complete resolution of symptoms. A literature review of more serious parotid injuries supported the conservative management policy.

(Emerg Med f 2001;18:402-403)
\end{abstract}

Keywords: parotid gland; trauma

Trauma to the parotid gland is fortunately rare. Being well protected by a thick capsule, and situated behind the strong mandibular skeleton, the parotid can only usually be breeched by a penetrating wound, or by a violent external force with fracture of the mandible, such as after a road traffic accident. In these instances, the trauma to the gland parenchyma is usually superseded by trauma to other, more vital structures, necessitating surgical intervention.

We present a case in which a relatively minor blunt force to the side of the face caused disruption of the parotid gland parenchyma, with leaking of saliva from the gland, in the absence of any other injury. We present the radiological findings, and discuss an empirical basis for management.

Case report

A 14 year old boy presented with acute left facial swelling, 16 hours after being struck accidentally, just anteriorly to the pinna, by another child's knee. The swelling, which was not particularly painful, had gradually increased in size since the injury. The patient was otherwise in good health and had been vaccinated against mumps as a young child.

On examination there was marked left facial and cervical swelling. This was not tender and there was no trismus. There was no clinical evidence of fracture of the facial skeleton. The cranial nerves and in particular the facial nerves were functioning normally. The patient was not feverish and there were no symptoms or signs of airway compression.

Computed tomography showed marked soft tissue swelling involving the left parotid gland (fig 1). There was extensive oedema of the

^ Mr O D Smith has died since this article was written.

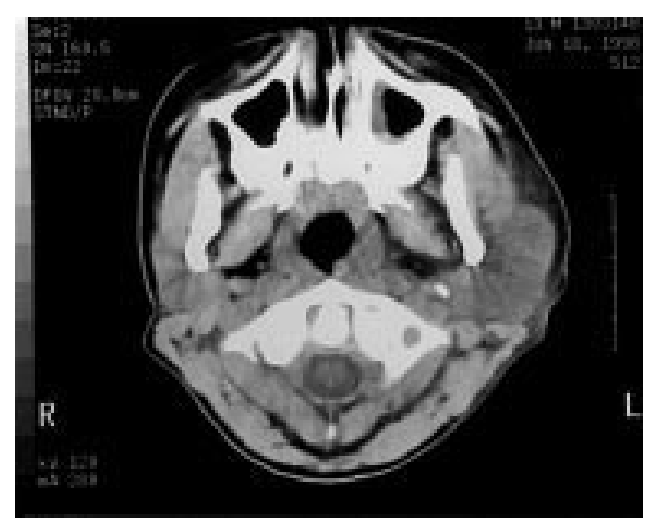

Figure 1 Computed tomography showing diffuse swelling of the left parotid gland, with oedema of the overlying subcutaneous fat.

overlying subcutaneous fat with loss of clarity of the fascial planes. There was no evidence of haematoma or underlying bony injury. A parotid gland rupture was suspected; the patient was admitted to hospital and treated with hyoscine to reduce salivary flow and antibiotics as prophylaxis against secondary infection.

On the day after admission a sialogram was performed, to confirm the diagnosis and exclude a major ductal injury that would require repair or ligation. The opening of Stensen's duct was cannulated and contrast injected gently by an experienced radiologist. The ductal system was seen to be intact (fig 2). A non-uniform abnormality of acinar pattern was observed early in the procedure, which was well tolerated by the patient. This was distinct from the flush of overfilling, which tends to be diffuse, occurs later in the procedure and is painful. Recurrent parotitis of childhood was also excluded because of the unilateral clinical findings and the absence of recurrent symptoms. The appearances were therefore

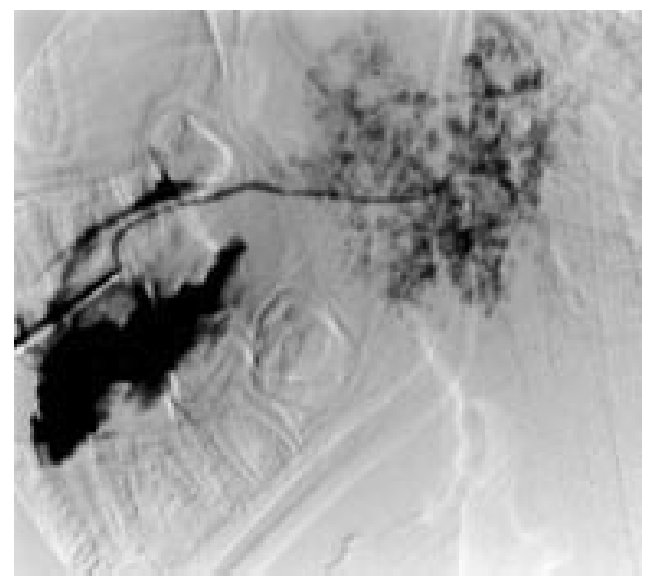

Figure 2 Left parotid sialogram, 24 hours after injury, showing an intact duct system but disruption of the normal acinar pattern.
Accepted for publication 16 October 2000 


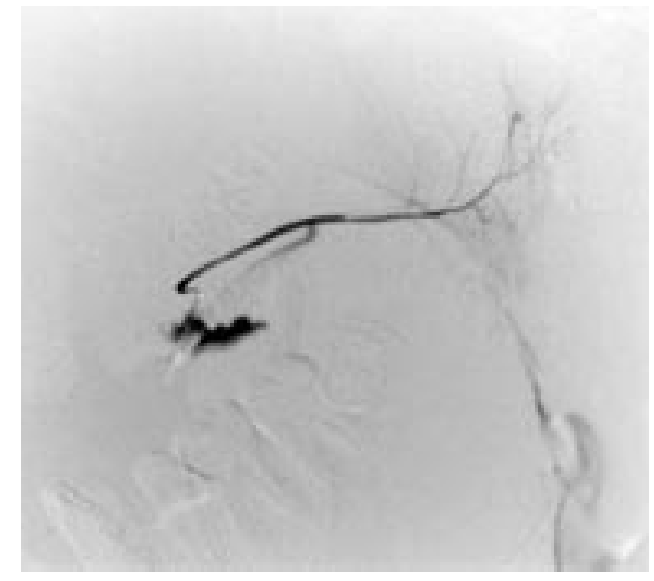

Figure 3 Left parotid sialogram, six weeks after injury, showing normal anatomy. Other images in the series were also normal. Although less filled than figure 2, acini are clearly visible, confirming that adequate pressure was applied on injection of contrast.

attributed to a rupture of the parotid parenchyma.

During the 48 hours of admission the facial swelling subsided and the patient was discharged home. When reviewed in the outpatient department six weeks later he was asymptomatic and there were no abnormal clinical findings. A repeat sialogram was performed, showing normal parotid architecture (fig 3).

\section{Discussion}

Trauma to the parotid gland is rare. It is usually the result of a penetrating wound, such as in wartime, or after a criminal assault. The largest published series of such injuries dates from the first world war, when Morestin reported a series of 62 cases of parotid fistulas after battlefield wounds. ${ }^{1}$ Initially, treatment consisted of surgically draining the fistula into the oral cavity. Later a simpler solution was found: the proximal duct was ligated, causing the gland parenchyma to atrophy and saliva production to cease.

Subsequent workers have found that conservative management of parotid duct injuries is adequate. In a series of 14 cases of penetrating injuries, Landau and Stewart concluded that systemic probanthine, intravenous fluids, a nil by mouth regimen, and external pressure would produce resolution of symptoms, even in the presence of a fistula or sialocele. ${ }^{2}$ In their series, antibiotics were given only if there was clinical evidence of infection, and surgical exploration was reserved for those patients presenting within 24 hours of the injury. A series by Lewis and Knottenbelt also concluded that conservative management was adequate for parotid duct injuries.
Perhaps the most clinically significant aspect of penetrating injury to the parotid gland is disruption of the facial nerve. It is essential when managing such patients that facial nerve function is carefully documented and recorded, especially as early surgical exploration of an injured nerve can produce a favourable outcome. Youngs and Walsh-Waring reported three patients with facial palsy after open trauma, all of whom underwent surgical exploration of the nerve, and all of whom subsequently achieved a good recovery. ${ }^{4}$

Trauma to the salivary glands in the absence of a penetrating injury is particularly rare. The force required is considerable, and there is usually an associated skeletal injury, to the mandible or temperomandibular joint. ${ }^{56}$ Roebker et al reported a case in which the submandibular salivary gland was ruptured after blunt trauma sustained in a road traffic accident. ${ }^{7}$ Computed tomography showed a similar picture to the current case: the gland was swollen and there was an adjacent lucent area. There have been no case reports, however, in which parotid gland has ruptured after a minor external force, in the absence of a penetrating wound.

\section{Conclusion}

Trauma to the parotid gland parenchyma and duct may occur even after a minor blunt trauma. It produces a clinical picture of facial swelling with minimal pain, and may be diagnosed by computed tomography or sialography. Injury to the skeletal structures and facial nerve needs to be excluded, after which a conservative approach to management is appropriate.

\section{Contributor}

Dan Smith and Don McFerran were responsible for the patient's care throughout the clinical course, identifying the rarity and significance of the case. They also jointly conducted the literature review and prepared the text of the manuscript. Nagi Antoun, an experienced consultant neuroradiologist, conducted and interpreted the radiographic images of figures 1 to 3 . He and interprete the final manuscript, and provided expert opin also proof read the fion ion into the condition of parotid trauma a
diagnosis of recurrent parotitis of childhood.

1 Morestin M. Contribution à l'etude du traitement des fistules salivaires consécutives aux blessures de guerre. Bulletin et Memoires de la Societe des Chirurgiens de Paris 1917;43:845-55.

2 Landau R, Stewart M. Conservative management of post-traumatic parotid fistulae and sialoceles: a prospective study. Br F Surg 1985;72:42-4.

3 Lewis G, Knottenbelt JD. Parotid duct injury: is immediate surgical repair necessary? Injury 1991;22:407-9.

4 Youngs RP, Walsh-Waring GP. Trauma to the parotid Youngs RP, Walsh-Waring GP. Traum
region. $\mathcal{F}$ Laryngol Otol 1987;101:475-9.

5 Ohlson NR. Traumatic lesions of the salivary glands. Otolaryngol Clin North Am 1977;10:345-50.

6 Shetty DK, Rink B. Effects of direct blunt trauma on the salivary glands. Deutsch Zahn Mund Kieferheilk 1974;62: $148-57$

7 Roebker JJ, Hall LC, Lukin RR. Fractured submandibular gland: CT findings. F Comput Assist Tomogr 1991;15:10689. 